\title{
SOBRE LA MEMORIA Y LA EXPERIENCIA DE CONFORMACIÓN EN EL SABER SOBRE SÍ MISMO EN XAVIER ZUBIRI
}

\section{REGARDING MEMORY AND THE EXPERIENCE OF CONFORMATION IN SELF-KNOWLEDGE IN XAVIER ZUBIRI}

Jesús AlBerdi SuduPE*

Fundación Xavier Zubiri

Resumen: Memoria y experiencia están muy próximas entre sí en el ejercicio del entendimiento humano. La conformación es una de las modalidades en que se da la experiencia, una modalidad decisiva para el saber de uno mismo. Al contrario que Aristóteles, Xavier Zubiri piensa que la memoria es hija de la experiencia, y no a la inversa. Ésta no es primariamente y sólo empeiria, con la contribución de la mneme, en el flujo constante y cambiante de la percepción sensible. Aristóteles distinguió este almacenamiento, mneme, y la reminiscencia activa, anamnesis, pero no aplicó esta distinción a la experiencia. La experiencia es parte de la actividad racional humana, y consiste en la probación física de realidad de las construcciones lógicas y racionales que elaboramos a partir de los recuerdos decantados en la memoria, individual, social e histórica. Tratándose de uno mismo, y a diferencia de lo que podemos llegar a saber de otras cosas y de otras personas, el modo de hacer la probación física de lo que postulamos cada uno de sí mismo, adquiere unas características propias. Es lo que Zubiri llama experiencia de conformación de uno mismo. Su resultado es el saber de uno mismo.

\footnotetext{
*Fundación Xavier Zubiri. Madrid. Calle Núñez de Balboa, 90, 5. Madrid, 28006. jalbsud@ gmail.com
} 
Palabras Clave: Experiencia, inteligencia sentiente, memoria, conformación, saber de sí mismo, Xavier Zubiri.

Aвstract: Memory and experience are very close to each other in the exercise of human understanding. Conformation is one of the modalities of experience, a decisive modality for self-knowledge. Unlike Aristotle, Xavier Zubiri thinks that memory is the daughter of experience. Experience is not primarily and uniquely empeiria, with the contribution of the mneme, in the constant and changing flow of sense perception. Aristotle distinguished between this storage, mneme, and active reminiscence, anamnesis, but he did not apply this distinction to experience. Experience is part of rational human activity, and it consists of the physical probation of reality of the logical and rational constructions that we create from stored memories in individual, social and historical memory. With reference to oneself, and unlike what we can manage to know about other things and other people, the way of doing the physical probation of what each of us postulates about him- or herself acquires its own characteristics. It is what Zubiri calls the experience of the conformation of oneself. Its result is self-knowledge.

KEY WORDs: Experience, sentient intelligence, memory, conformation, self-knowledge, Xavier Zubiri.

\section{Introducción. Memoria, experiencia, conformación de sí como modo de experiencia, y saber de sí mismo}

Conill (1998: 150) indica que la historia de la filosofía occidental, en alguna de sus vertientes, puede ser leída siguiendo las huellas del argumento de una "tensión" que se va manteniendo a través de los siglos, una tensión vigente todavía en la actualidad, y que va desbrozando los caminos del pensar filosófico. Una tensión del pensar que se escinde entre el "métodológico (logikôs)" y el "método experiencial (physikôs)".

Ejemplos destacados de una y otra manera de proceder en la elección del camino en el pensar para el enfrentamiento con las cosas serían Platón y Aristóteles, respectivamente. Aunque, como todo juicio tan general, este enunciado requeriría muchas precisiones. Porque, ni Platón evita algunos caminos experimentales, ni Aristóteles está alejado de ninguna manera de unos caminos lógicos. Todo lo contrario, ambos caminos están estrechamente entrelazados en los dos 
filósofos. Su referencia es más bien pedagógica. "Vía lógica” o racional, podría llamarse la primera, y podríamos destacar en ella que la necesidad del pensar vendría dada sobre todo a partir de la elaboración de las preguntas y respuestas que surgen entre los hablantes en un contexto de diálogo entre personas, que se preguntan entre sí sobre las cuestiones más diversas en relación con la naturaleza, el cosmos, y la vida en común, a modo de lo que ocurre en los diálogos platónicos.

La segunda, la "vía experiencial”, estaría por su parte promovida no tanto o inicialmente por el buen desarrollo de un diálogo entre las personas, sino por la observación originaria, callada, asombrada, del permanente movimiento y cambio físico que advertimos en el mundo, en la vida, en las personas y en nosotros mismos. Y a partir de tal observación, se harían patentes nuestras dificultades y nuestra inherente inquietud para intentar entender dicha inestabilidad, ver si algo permanece, y expresarlo adecuadamente.

Primaria instalación en un lenguaje dialogado, en el primer caso. O primario observar silencioso para luego ser expresado, en el segundo. Doble vía que, a partir de Platón y de Aristóteles, ha seguido por supuesto desarrollos muy diversos. Diversidades, por otra parte, que no han de entenderse necesariamente como constitutivas de una disyunción excluyente entre ambas opciones, como no lo fueron en Platón y Aristóteles. Disyunción para la que el autor propone la solución de una unitaria "razón experiencial" que las sostiene y que da cuenta del lugar único de la confluencia de las dos vertientes del pensamiento con sus muchas variantes (Conill, 1991: 150).

Para fundamentar esta propuesta convergente en la que poder aunar experiencia y razón, razón experiencial o experiencia racional, el autor recurre, entre otras $^{1}$, a una cita de Xavier Zubiri en su obra temprana Naturaleza, Historia, Dios (primera edición de 1944) (NHD), cita que nos emplaza precisamente en el comienzo de nuestra reflexión sobre la experiencia en este trabajo, y en particular sobre la experiencia de sí mismo, en Xavier Zubiri, objeto principal de este estudio.

\footnotetext{
${ }^{1}$ Además de la referencia a Zubiri, "hay que atender realmente a las diversas concepciones de la experiencia, desde la aristotélica, pasando por la kantiana y hegeliana, hasta la nietzscheana y otras filosofías contemporáneas proclives a un pensar experiencial, como es el caso, por ejemplo, de cierto pragmatismo, las hermenéuticas, el raciovitalismo y la noología" (Conill, 1998: 152-153).
} 
La cita misma ya nos advierte sobre algunas características esenciales del acceso al saber de uno mismo que van a aparecer más adelante. En particular, podemos decir anticipadamente que en el saber sobre sí mismo se trata de un saber logrado en actos de intelección sentiente, y, además, de un saber en el que intervienen la memoria y la experiencia humana, esta última según varias de sus distintas modalidades (Conill, 1998: 153).

El saber de uno mismo es para Zubiri el resultado, el decantamiento o sedimento, de los logros que va obteniendo el entendimiento humano en sus actos de intelección sentiente como actos de impresión de realidad. Estos actos de intelección sentiente están modalizados en aprehensión primordial, logos y razón.

Dicho de manera esquemática, "el inteligir en todo su despliegue queda modalizado como entendimiento, cuyo acto propio es el comprender, que genera un estado, el saber. Al entender las cosas, quedo sabiendo" (Gracia, 2007: 168)².

2 D. Gracia remite a Zubiri X. (Inteligencia y Razón (IRA), 1983: 341-350). Se trata del tercer y último volumen de la trilogía que compone el título general de Inteligencia Sentiente: Inteligencia y Razón.

Con anterioridad a ese texto, véase una primera propuesta de lo que sea "saber" para Zubiri en ¿Qué es saber? (Publicado en Naturaleza, Historia, Dios (NHD), 1987: 33-59). Trabajo perteneciente a su "primera época", según dice el propio autor en el Prólogo a la edición norteamericana de Naturaleza, Historia, Dios. Dice textualmente: "según me expresaba en el estudio ¿Qué es saber?, lo que yo afanosamente buscaba es lo que entonces llamé Lógica de la realidad".

En Zubiri X. (1935) Filosofía y Metafísica, Cruz y Raya, no 10 (editado años más tarde, como parte de un libro editado por Germán Marquínez Argote: Zubiri X. (2002). Sobre el problema de la filosofía y otros escritos (1932-1944), (SPFOE), Madrid: Alianza Editorial, 179-215) Zubiri habla de varias acepciones de "saber". Primero, un saber como "discernir", distinguir lo que es algo de lo que no es. Segundo, saber puede entenderse también como "definir", o decir "qué" es algo, mostrarlo. Y, en tercer lugar, saber como "de-mostrar", y "entender" algo en su suficiencia, en su ousía o sustancia, en su necesidad interna de ser como es, no sólo en su qué, sino en su por qué es como es.

Ahora bien, "no todo es quizá demostrable en el mismo sentido. No todo puede ser entendido de la misma manera. Ni todas las cosas, ni todo en ellas nos es igualmente accesible." (Zubiri X. SPFOE, 2002: 194). El acceso a las demostraciones sobre sí mismo tiene sus características propias, que Zubiri desarrollará sobre todo en un Curso oral de 1967 (publicado en Zubiri X. El hombre: lo real y lo irreal (HRI), 2005), y en Zubiri, IRA, 1983. Se trata de la "conformación".

La vía de acceso es lo que los griegos llamaron "methodos" "lo mismo los sentidos que el logos son métodos. Pero preferentemente se concentró la atención en el logos por ser la vía que nos conduce a entender las cosas" (Zubiri X. SPFOE, 2002: 194).

Zubiri dedicará también especial atención a la contribución de los distintos órganos de los sentidos (Zubiri X. Inteligencia sentiente. Inteligencia y realidad. IRE, 1984: 100 ss.). De tal 
Entre los antecedentes de Zubiri que pueden evocarse en este tema de la experiencia, baste recordar a Kant en la Introducción a su Crítica de la razón pura. Kant indica que, aunque todo nuestro conocimiento comienza en la experiencia, ya que el conocimiento se inicia con las impresiones sensibles de las que luego puede disponer el entendimiento, no todo él procede de la experiencia. Ya que las impresiones sensibles, por sí mismas, sin la ordenación objetiva que les imprimen las conformaciones del entendimiento, no saldrían de la confusión sensorial originaria en la que se nos da el mundo (Conill, 1998: 155).

El concurso de la memoria en el entendimiento es una participación como depósito de percepciones y de elaboraciones lógicas y racionales. La memoria interviene en diversos momentos de la actividad del entendimiento, y entre ellos en la actividad de la razón y en su experiencia. De tal modo que, ambas, experiencia y razón, que inicialmente son dos caminos divergentes, resulta que al menos en Xavier Zubiri, están estrechamente vinculadas, e intervienen ambas conjuntamente en el desarrollo del pensar filosófico.

Para Aristóteles, la memoria actúa reteniendo una cierta mismidad sustancial estable gracias a las repeticiones sensoriales de la aisthesis, a partir de la familiaridad que surge en ella ante tales repeticiones sensoriales, en contraste con el constante cambio del flujo vivencial de otras percepciones todas pasajeras. Con esa familiaridad se retienen los rasgos que luego harán posible la construcción de lo que podrían ser en el mundo las cosas, o sustancias, dotadas de cierta estabilidad. Esta elaboración o construcción es objeto de las modalizaciones de la intelección sentiente en logos y razón (Zubiri, HRI, 2005: 146) ${ }^{3}$.

manera que en el acceso a sí mismo hay algún sentido (cenestesia, sensibilidad visceral) que adquiere un privilegio en su relevancia metafísica en el acceso al "mî" como primera forma de darme a mí mismo.

3 Zubiri, X. (1984). Inteligencia sentiente. Inteligencia y realidad, Madrid: Alianza Editorial, en particular, el Capítulo V: La índole esencial de la intelección sentiente (133-189); y el Capítulo VI: Idea de realidad de lo sentientemente inteligido (189-229). Pintor-Ramos, A. (1983). Génesis y formación de la filosofía de Zubiri. (2a edic.), Salamanca: Universidad Pontificia de Salamanca. Ferraz Fayos, A. (1988). Zubiri: el realismo radical, Madrid: Cincel. Pintor-Ramos A. (1994), Ámbito de la realidad en Zubiri, en: Pintor-Ramos A. (1994). Realidad y verdad. (Las bases de la filosofía de Zubiri), Salamanca: Publicaciones Universidad Pontificia de Salamanca, 56-71. Marquínez Argote, G. (2006). "Realidad, historia de una palabra desde sus orígenes latinos hasta Zubiri”, en Cuadernos salmantinos de filosofía, 33: 145-180. Gracia, D. (2007). La realidad (El momento noemático de la aprehensión humana), en: Gracia D. (2007). Voluntad de verdad (Para leer a Zubiri), Madrid: Triacastela: 169211. González, A. (2013). Surgimiento. Hacia una ontología de la praxis, Santafé de Bogotá: 
En un siguiente momento, estas construcciones han de ponerse a prueba en su confrontación racional con la realidad. En esto consiste propiamente la experiencia, en probación física de realidad. Probación que Zubiri atribuye a la razón humana, y por tanto la experiencia en Zubiri es un término que corresponde a la razón. Probación que, de tratarse de las construcciones elaboradas sobre uno mismo, adquiere algunas características propias y distintivas respecto a la probación de cosas y de otras personas. Son las características propias de la conformación, a diferencia del experimento, o de la compenetración interna y de la comprobación, las otras formas de probación física de realidad para Zubiri.

\section{Los dos primeros términos: "memoria" y "experiencia" en Xavier Zubiri}

Precisamente, Zubiri hace referencia a que la vida humana es un flujo cambiante y constante, inasible, de aferencias sensoriales, tendencias, etc. Todo va cambiando como en el río de Heráclito. Todas las cosas, las personas, y uno mismo, van/vamos cambiando sin cesar.

Esto no es todo. No todo pasa, sin más, o solamente pasa, más o menos fugazmente, para caer de inmediato en el olvido. Ese permanente cambio del río también deja entrever "lo que" está de paso en las aguas del río, o el agua misma del río en su pasar. De tal forma que algunos caracteres del flujo sensorial permanecen detenidos con alguna estabilidad transitoria, como "cosas", personas, uno mismo, en todos los casos con cierta "mismidad" de algo a pesar de sus cambios (Zubiri, IRA, 1983: 226) ${ }^{4}$, mismidad que se decanta en la memoria del aprehensor.

Aprehensor quien a su vez también es algo/alguien relativamente estable como testigo del permanente cambio. Y lo que queda decantado en su memoria

Ediciones USTA. González, A. (2015). "Mismidad de acto: Aristóteles, Heidegger y Zubiri”, en Pensamiento 71: 353-367.

${ }^{4}$ En el ámbito psicológico y psicopatológico, el Psicoanálisis ha descubierto que la tendencia a la repetición es un mecanismo básico de la vida psicológica, tanto sana y patológica. Y en algunos casos patológicos adquiere una gran importancia para el sufrimiento humano (Laplanche J., Pontalis J.-B., 1983: 366). 
despertará una familiaridad en el reconocimiento de algunas características que vuelven y se repiten en el cambio constante, y que de esa forma dan unos asideros estables en los que asentarse. A pesar de la fugacidad, o a la vez que ella, queda una cierta estabilidad de algunos entes, objetos, etc., de uno mismo, y del mundo. Estabilidad que se nos da como decantada en la memoria. Ésta sería la manera de entender la memoria por parte de Aristóteles, memoria como mnemé, memoria retentiva, almacén de percepciones repetidas. En la memoria se van depositando los recuerdos que van pasando de un mismo objeto y con ellos sedimentamos una experiencia de cierta estabilidad de ese objeto, que nos permitirá reconocerlo cuando vuelva a aparecer y pensar en él. De este modo, para Aristóteles, "la experiencia es hija de la memoria" (Zubiri, HRI, 2005: 146).

Zubiri invierte los términos aristotélicos. La memoria hace posible elaborar nuestras construcciones lógicas y racionales sobre lo que cada cosa pueda ser, pero luego tendremos que poner a prueba esas construcciones contrastándolas con la realidad. Este contraste probatorio es el momento de experiencia, momento decisivo al que queda subordinada la participación previa de la memoria. De esta forma, para Zubiri resulta que la memoria es hija de la experiencia. Porque la memoria sería entendida así, no ya sólo como retentiva, como mnémé, mero depósito de huellas o recuerdos almacenados, sino como memoria con la opción de una reminiscencia también activa, como anamnésis, memoria activa en la elaboración de sus recuerdos y su proyección al contraste con la realidad 5 . Y para Zubiri, "lo que pasa es que Aristóteles, que distinguió muy adecuadamente entre la retentiva y la reminiscencia, no aplicó esa distinción a su concepto de la experiencia" (Zubiri, HRI, 2005: 147).

Primer paso, elaborar desde la retentiva mnésica de la memoria, recordándolas por reminiscencia activa o pasiva, lo que las percepciones sensoriales reales serían entre otras cosas reales y podrían ser en la realidad. Porque, ¿qué son esas cosas, esas personas, yo mismo? Para responder a estas preguntas, primero el hombre tiene que recurrir al ejercicio de la irrealización de contenidos adquiridos por los sentidos y almacenados en la memoria, contenidos de lo que las

\footnotetext{
${ }^{5}$ Como contraste entre las dos modalidades de la memoria: Ricoeur, P. (2003). La Memoria, la Historia, el Olvido, Madrid: Trotta.

Para González (1999: 13), "la escolástica de raíz aristotélica sistematizó estas ideas en su esquema de acto y potencia. La memoria sería una potencia que puede pasar a acto. Y ese acto de rememoración consistiría en la actualización de esa potencia o capacidad". Véase también la distinción que hace el autor (González, 1999) entre "memorial" o "monumento" y "memoria".
} 
cosas, las personas y uno mismo, serían y podrían ser unas frente a otras y en el mundo. Buscamos saber lo que comparativamente es cada una, las desconocidas comparadas con las sabidas, para seguir viviendo con todas ellas. Son contenidos adquiridos en intelección sentiente y que van quedando en la memoria y nos permiten elaborar ideas de lo que es cada cosa, cada persona, y comparar esos contenidos con los nuevos que van llegando. Este ejercicio comparativo en la memoria es una necesidad vital. "El hombre necesita forzosamente figurarse, (...) forjar lo irreal precisamente para estar en la realidad; no solamente para comprenderla, sino para estar físicamente en la realidad, apoyarse en ella, para hacer su vida -para hacerse en ella a sí mismo-” (Zubiri, HRI, 2005: 129).

La segunda parte del Curso/libro El Hombre: lo Realy lo Irreal (Zubiri, HRI, 2005: 70-130) responde a la pregunta de por qué se da esta necesidad, a la pregunta de por qué el hombre tiene necesariamente que forjar con la memoria y la familiaridad las construcciones de contenidos irreales, para seguir viviendo entre las cosas concretas con las que está instalado en la realidad, y no puede no hacerlo.

La respuesta no está en la propia "vida" como referente último, Zubiri no es un vitalista a modo Bergson, o incluso de Ortega y Gasset. Sino que para él la vida se apoya a su vez en la estructura de la aprehensión de realidad, de la intelección sentiente, primera instancia que nos instala impresiva o sentientemente en la fluencia de la vida, e intelectivamente en la realidad que fluye en la vida, y que como realidad se contempla a sí misma en su propia fluencia. Para Zubiri, la intelección sentiente del entendimiento humano es la última instancia, y no la vida. En esa intelección sentiente se nos dan las cosas, no en una vertiente idealista constituídas por el propio entendimiento, sino como reales, como "de suyo". Y en las cosas reales se nos da "la" realidad, que transciende la talidad concreta de cada cosa real ${ }^{6}$.

En la realidad no estamos primariamente como seres vivientes. "Estoy primariamente porque este ser viviente que yo soy es inteligencia sentiente. Estamos en la realidad no solamente aprehendiendo lo que ya es en una intelección sentiente, sino que estamos físicamente en la realidad (...) Y este estar es fluente" (Zubiri, HRI, 2005: 193).

\footnotetext{
${ }^{6}$ Véase Zubiri, IRE, 1984, especialmente el Cap. VI: "Idea de realidad de lo sentientemente inteligido”, 1. La realidad. 2. Lo real. 3. El ser de lo real: pp. 189-229.
} 
Esta necesidad surge de este hecho fundamental, de que en la aprehensión primordial en la que quedamos instalados en intelección sentiente (y en sentimiento afectante, y en voluntad tendente) no solo estamos "aprehendiendo" las cosas reales y en ellas la realidad, sino que al aprehenderlas "estamos" físicamente en las cosas, y en ellas y con ellas en la realidad, haciendo énfasis, primero, en este "estar" del "estar aprehendiendo" de la aprehensión intelectivo-sentiente.

$Y$, en segundo lugar, resaltando que en este estar en ambas, entre las cosas reales, y en la realidad como tal, se abre entre ellas, cosas concretas y realidad inespecífica, lo que llama provisionalmente una "diferencia". Diferencia que se muestra como una oquedad o vacío que el hombre "tiene que llenar" para seguir viviendo, llevado o arrastrado inexorablemente en esa continua fluencia del vivir. De las cosas sólo aprehendemos "algo", las aprehendemos parcialmente.

Por este motivo es una oquedad de contenido de las cosas, de insuficiencia en el contenido aprehendido, no de formalidad de realidad. Una oquedad que se presenta con poco o apenas contenido, unas veces. Otras, con un contenido pobre. O también, sobre todo, con un contenido indefinido.

Una oquedad que se abre a las opciones de la libertad de la construcción de contenidos irreales por parte del hombre, para ir alojando en ella o llenarla con algo que le dé una cierta compacción, una riqueza y un carácter más definido para la oquedad que ha quedado abierta en la aprehensión humana (Zubiri, HRI, 2005: 193).

Además del empuje a seguir viviendo, en esta fluencia como modo de estar en la realidad, se da una notable particularidad. En ese continuo fluir de constante cambio, el hombre se encuentra con recurrencias o repeticiones. Recurrencias imprecisas, no exactamente las mismas de una presentación a otra, aunque al hombre le "parecen" las cosas aproximadamente las mismas que fueron anteriormente, y comienzan por volver, repetirse, con cierta estabilidad, proporcionando en el constante cambio un asidero que permanece fijo en el fluir, unas referencias donde poder apoyarse.

Y ocurre algo muy importante. Construir el contenido de lo que puedan ser las personas y sobre todo uno mismo, a partir de la memoria individual y colectiva que va almacenando los contenidos, es mucho más difícil que construir el contenido de otras muchas cosas. 
En palabras del propio Zubiri, "comoquiera que sea, la figuración -esto es un hecho obvio- tiene más complicaciones tratándose de personas que tratándose de cosas. (...) Con lo cual la probación y, por consiguiente, la experiencia, tiene un carácter muy distinto tratándose de personas y tratándose de cosas" (Zubiri, HRI, 2005: 158-159). Y en especial, tratándose de uno mismo. Porque, si la experiencia de otras personas es en cierta manera "extrínseca" (Zubiri, HRI, 2005: 160), y para ello Zubiri ańade que deja de lado las relaciones interpersonales, cuando se trata de saber sobre uno mismo, un saber "intrínseco", aparece una gran dificultad que choca contra la aparente transparencia inmediata de la res cogitans cartesiana para sí misma: "en primer lugar, en la dificultad insuperable en cierto modo, de averiguar cuál es la idea exacta que uno se forma de sí mismo" (Zubiri, 2005: 160).

Resulta que en el acceso a sí mismo nos encontramos con una severa opacidad que envuelve o forma un velo sobre ese sí mismo, una especie de velo de Maya para Schopenhauer, una opacidad muy complicada de desvelar y de lograr analizar $^{7}{ }^{8}$. Hay una "especial dificultad" para construir las ideas, los esbozos irreales sobre sí mismo en conjunto, estructura o sistema psico-orgánico9?. Frente a las cosas, o las demás personas, el sí mismo es el "objeto" - "objeto" con los reparos sobre la inadecuación del término-, más próximo, por un lado, y paradójicamente, más esquivo y difícil de aprehender, para uno mismo.

[Y no sólo eso,] segundo, y sobre todo, en que exacta o inexacta esa idea que uno se ha formado de sí mismo esa figuración pertenece intrínseca y formalmente a la propia realidad de cada cual. Y esto es lo que hace que el

\footnotetext{
${ }^{7}$ Res en Descartes, no tiene la fuerza de la "sustancia" aristotélica. "aquí res no significa cosa, esto es sustancia u ousía en sentido físico en Aristóteles, sino tan sólo lo que la escolástica entendía por res, a saber, la esencia en su sentido latísimo, el qué." (Zubiri, SE, 1985: 4).

${ }^{8}$ Carruthers, P. (2011). The Opacity of Mind: An Integrative Theory of Self-Knowledge, Oxford: Oxford University Press. Coliva, A. (2012). The Self and Self-Knowledge, Oxford: Oxford University Press. Descartes, R. (1977). Meditaciones metafísicas con objeciones y respuestas, Madrid: Alfaguara. Fernández, J. (2013). Transparent Minds: A Study of SelfKnowledge, Oxford: Oxford University Press.

${ }^{9}$ Los modelos más inmediatos son los de la aprehensión de "cosas" (sobre todo mediante la vista, o ésta recubriendo otros sentidos). Pero estos modelos fallan no pocas veces. El ejemplo de los cuerpos macroscópicos en la experiencia sensible ordinaria para utilizarlos como modelos para los corpúsculos subatómicos en Física, es ilustrativo. (Zubiri, X. IRA, 1983: 22-258). Esos modelos de cosas y organismos, difícilmente extensibles a subsistema psíquico. ¿Qué modelos emplear para el subsistema psíquico? Zubiri critica en más de una ocasión que la "estratificación" del subsistema psíquico sea un modelo correcto para su representación (Zubiri, X. SH, 1986: 495).
} 
hombre huya, en cierto modo o tenga la tendencia a huir de sí mismo. Pero esa huída es también un modo de experiencia. (Zubiri, HRI, 2005: 160)

Por lo tanto, las dificultades las hay, tanto en lo referente a la memoria en la construcción de los contenidos de las personas, pero sobre todo de uno mismo, en comparación a los contenidos de otras cosas, como en lo referente a ulterior la probación física de esos contenidos en la experiencia. Tanto que en este segundo momento tiene cada cual la tendencia a huir de sí mismo ${ }^{10}$.

La probación física en la realidad es el segundo paso que buscamos, el de la experiencia. El primero, que hemos relacionado con la memoria, es la elaboración de las construcciones sobre lo que pueda ser yo mismo desde la memoria y desde otras capacidades humanas. Uno se figura a sí mismo de una cierta manera. Y solamente la probación a que uno se somete a sí mismo pone en claro si uno es o no es como se ha figurado que era (Zubiri, HRI, 2005: 158-159). El siguiente paso, el segundo, es acudir a la experiencia, desde la elaboración a la probación física en la realidad de las construcciones irrealizadas.

Zubiri distingue varias acepciones de la experiencia ${ }^{11}$ :

a) El primer filósofo que se hace cuestión temática de la experiencia es Aristóteles. El hombre y los animales tienen percepciones sensibles. Y la mayoría de animales tienen memoria, en la que se van depositando recuerdos. Los recuerdos referidos a un mismo objeto constituyen la experiencia de ese objeto, y en este sentido puede decirse que la experiencia es hija de la memoria. La memoria como reconocimiento o familiaridad con lo que nos va llegando a la percepción. Si lo percibido ha sido registrado anteriormente y queda depositado en la memoria, al llegar de nuevo nos produce una familiaridad. Y la experiencia es esta familiaridad con las cosas que vuelven, que reconocemos como las mismas. Experiencia es de este modo lo empírico, procede de los sentidos, a diferencia de lo racional o intelectivo, que procede de la razón (Zubiri, HRI, 2005: 145-146).

\footnotetext{
${ }^{10}$ Frente a la angustia de Heidegger, véase la propuesta de Zubiri en un texto originario de 1961: Zubiri X. (1992). "Las fuentes espirituales de la angustia y de la esperanza" (1961), en: Sobre el sentimiento y la volición (SSV), ed. de D. Gracia. Madrid: Alianza Editorial: 393407. Véase también la referencia de Zubiri a la "inquietud metafísica” en Zubiri X. (1984) El hombre y Dios (HD), Madrid: Alianza Editorial: 99-109.

11 Conill, J. (1998). "Concepciones de la experiencia", en Diálogo filosófico 41: 148-170. Zubiri, X. (1983). Inteligencia y razón, IRA, Madrid: Alianza Editorial. VI.2.3. "El método como experiencia": 222-258.
} 
La experiencia como un "sentir", un sentir con memoria (Zubiri, HRI, 2005: 150).

b) Kant, en su Introducción a la Crítica de la razón pura, acepta que todo nuestro conocimiento comienza en la experiencia sensorial. Pero esa información no es sino el "material bruto" sobre el que una compleja actividad intelectual elabora lo que llamamos la figura de un "objeto", el objeto, “...de estos objetos cuyo conjunto llama Kant justamente la experiencia” (Zubiri, HRI, 2005: 148). La experiencia como una "elaboración" intelectual del objeto (Zubiri, HRI, 2005: 150).

c) Zubiri hace mención a la durée de Bergson, una noción de experiencia que se aleja del mero sentir empírico. Como también se aleja la noción de experiencia de Husserl, para quien la experiencia no es sólo el sentir, sino “....algo que se nos dé inmediatamente, originariamente, por sí mismo" (Zubiri, HRI, 2005: 149). De tal manera que también la imaginación nos permite tener las cosas delante de los ojos y formarnos ideas de las cosas.

d) Para Dilthey la experiencia es como un sedimento que va quedando en la persona a lo largo de su vida. La experiencia es una "elaboración" de la vida (Zubiri, X. HRI, 2005: 150).

Para Zubiri, la experiencia no es algo que resida solamente en los sentidos, ni siquiera reforzados con la retentiva de la memoria, algo empírico. La mismidad de algo no es cuestión de "retención empírica de cualidades" (Zubiri, IRA, 1983: 225), sino que lo retenido es una cosa inteligida como real.

Tampoco es elaboración intelectual (Kant) o vital (Dilthey) de los contenidos sensoriales en un segundo momento para constituir los objetos tal como se nos presentan en el conocimiento y en la vida, repectivamente. Hay una primaria unidad del sentir e inteligir.

La aprehensión de un contenido sensorial nos da también, y a la vez, en el mismo acto aprehensivo sin una ulterior elaboración, su formalidad de realidad, algo aprehendido es algo "de suyo" en la aprehensión impresiva sensorial. Y esta formalidad de realidad remite en el polo noemático de la aprehensión, no sólo a la memoria en el aprehensor, sino a la estructura de lo aprehendido. La familiaridad que las repeticiones del cambio permanente en la vida despiertan en la memoria, no reposan en última instancia en la propia memoria. Remiten 
a la estructura de aquel contenido que se repite, que es real, y al cual quedamos remitidos para buscar en ello la experiencia que nos proporcionará una comprensión y un saber.

En el caso de que el objeto sea uno mismo, la experiencia tendrá las características particulares de la "conformación".

\section{La "irrealidad" entre la memoria y la experiencia. Los dos siguientes términos: La "experiencia de sí mismo" entendida como "conformación", y "saber de mí"}

En el desarrollo del citado Curso de 1967 (publicado como Zubiri, HRI, 2005), Zubiri señala que la presencia de la irrealidad en la realidad, en este caso en la realidad de la vida humana, es un contrasentido que retrotrae nada menos que a la problemática del lugar del no ser en el ser desde Parménides.

En la vida humana, y frente al constante fluir cambiante de lo real, es sólo mediante el rodeo por una irrealidad como podemos estar en la realidad, y responder en ella a las exigencias de la realización, y de esa forma podemos pretender lograr una cierta comprensión de la configuración constantemente variable del ser de la realidad del mundo, y la del ser del Yo como ser de la sustantividad humana, en su actualidad mundanal ${ }^{12}$.

Lo irreal es, pues, un "ingrediente" de la vida humana, lo irreal está inscrito en lo real, lo real se va construyendo en la experiencia mediante el paso previo por la irrealidad. El hombre tiene que construirse él mismo la configuración que irá adquiriendo su Yo, y aquí interviene el paso por la irrealidad. No de forma arbitraria, lo irreal se va construyendo a partir de las recurrencias en la fluencia de lo real, recurrencias en las que interviene la memoria individual, colectiva e histórica, como sede de las repeticiones entre los cambios.

\footnotetext{
${ }^{12}$ Porque vivir es para el hombre, en última instancia, autoposesión de sí mismo en decurrencia; y autoposeerse es en definitiva construcción del ser del Yo, de la esencia abierta, en su actualidad mundanal (Zubiri X. HRI, 2005: 88-89).
} 
La enumeración de los distintos modos de irrealización y de la construcción de posibilidades racionales, varían un poco del Curso de 1967 (Zubiri, HRI, 2005) a cómo se plantean en la Trilogía (Zubiri, IRA, 1983), los dos principales textos en relación al tratamiento que hace Zubiri de la experiencia.

El método racional exige partir de un sistema de referencia, "que es siempre la realidad en tanto que actualizada en la aprehensión, y desde ahí construir un esbozo de posibilidades" (Gracia, 2007: 159). "Esbozo es la conversión del campo en sistema de referencia para la intelección de la posibilidad del fundamento" (Zubiri, IRA, 1983: 219).

El esbozo tiene un contenido que siempre es construido, y como esta construcción no está generalmente determinada en ninguna dirección obligada, la construcción es libre. Y, de esta forma, el esbozo puede adoptar modos muy distintos entre sí. Tan diversos que habrá que hacer con ellos una experiencia de realidad y ver su conformidad.

Desde el esbozo, la vuelta a la realidad, para ver si la realidad aprueba el esbozo. En esto consiste la "experiencia", probación física de lo real (Gracia, 2007: 160). Esa probación (del esbozo de posibilidades construido desde el sistema de referencia, que es siempre la realidad en tanto que actualizada en la aprehensión) es la mayoría de las veces compleja, tan compleja que adopta al menos cuatro formas.

Pasamos a enumerarlas, para detenernos en la más propia de la experiencia en el saber sobre uno mismo, la conformación.

1. "Experimento". Es una "manipulación” o una "provocación externa” a partir de un constructo esbozado de posibilidades de que algo aprehendido realmente sea en la realidad tal como lo hemos elaborado intelectualmente. (Zubiri, IRA, 1983: 247)

2. “Compenetración interna”. Se pretende que la cosa nos muestre su índole interna "desde dentro". Esto es posible en las realidades humanas, en las relaciones interpersonales. Es una dimensión que tiene mucho que ver con el conocimiento de sí mismo. Zubiri dice que una perikhóresis, de modos de actuar o de comportarse en algunas situaciones, "es lo que se expresa al decir, por ejemplo, que una persona ve por los ojos de otra” (Zubiri, IRA, 1983: 250). Es un tipo de experiencia difícil, y Zubiri advierte del riesgo de proyectar sobre la experiencia 
la idiosincrasia del experimentador. En el ámbito psicológico, es el mecanismo por el que una persona localiza en otra sus propios sentimientos, deseos, etc. (Laplanche, J., Pontalis, J.-B. 1983: 306-312).

3. "Comprobación”. En el caso por ejemplo de las realidades matemáticas, realidades postuladas (Zubiri, IRA, 1983: 254).

4. "Conformación". La experiencia de la propia realidad de uno mismo. No la aprehensión de uno mismo, de mi realidad, que se da en la modalidad sensorial cenestésica de la aprehensión primordial, ni su afirmación en un juicio de lo que soy en realidad. Sino que consiste en la integración de un "esbozo de posibilidades de lo que soy en mi propia realidad” (Zubiri, IRA, 1983: 256-7). "La probación consiste en tratar de conducirse uno conforme a lo esbozado; es, pues, un intento de conformación" (Gracia, 2007: 161). "Conformación: he aquí el modo radical de experiencia de uno mismo, es la radical probación física de mi propia realidad. Conocerse a sí mismo es probarse en conformación" (Zubiri, IRA, 1983:257).

Necesitamos averiguar, más allá de las acciones, de las vivencias sentimentales, llegar al modo como realmente soy como persona, mi personalidad. Y para ello necesito un método o vía que desde la realidad en la que estoy me conduzca a mi realidad profunda mediante una probación física de lo que he podido esbozar de mí mismo. Insertar los esbozos (esbozos irreales) de posibilidades de lo que puedo ser en el fondo de mi personalidad, en mi propia realidad. Insertar quiere decir conducirme en mi intimidad conforme a lo esbozado. "Como decía San Agustín, quaestio mihi factus sum, me he convertido en cuestión para mí mismo" (Zubiri, IRA, 1983: 255).

Va más allá del examen de conciencia y de un relato de mí mismo. Los relatos además pueden seguir orientaciones distintas. No es lo mismo la confesión de san Agustín en referencia a la presencia de Dios en su alma, que la confesión de Rousseau a la búsqueda de un análisis "natural" de su vida interior. Con todo, más allá del examen de conciencia y su relato, "conocerse a sí mismo es probarse en conformación” (Zubiri, IRA, 1983: 257).

Insistimos que el conocimiento de sí mismo no corresponde únicamente a la modalidad experiencial de la conformación. Uno mismo puede ser objeto de experimentos en distintas vertientes de su naturaleza. O de comprobación 
matemática. Y cómo no, puede someterse y de hecho se vincula de forma permanente en su vida a los avatares de la compenetración con otras personas.

Otras personas que ya están presentes en uno mismo en su constitución genética en cuanto que es engendrado desde otras personas de las que mantiene en sí una parte de material genético. Otras personas que están inmersas dentro de uno mismo desde los primeros cuidados que recibe al nacer, nińo o nińa que va elaborando su identidad en su establecerse en la recepción de esos cuidados. Y en más tarde al acceso a la cultura, a la historia, y al lenguaje, en los que se va constituyendo con mayor complejidad su propia identidad. Todo ello es parte de uno mismo, actúa desde "dentro" dentro de uno mismo ${ }^{13}$.

Desde "fuera", en las relaciones interpersonales, lo que otras personas conocen o esbozan de mí me lo pueden hacer saber, y eso pasa también a integrar mis esbozos, los hago míos, o los rechazo, en intelección sentiente. O me los dan no como un saber racional, sino que los recibo más "vivencialmente", en mi relación con ellos, sin palabras, "afectivamente". Esbozos en sentimiento afectante ${ }^{14}$, y en voluntad tendente ${ }^{15}$.

Pero las peculiaridades de esta modalidad de conformación hacen que sea una modalidad experiencial humana muy destacable para Zubiri, y le dedica especial atención en su análisis. Es una forma de conocimiento racional sobre sí mismo apoyada en una experiencia que no comparte su modo de darse, ni con la experimentación científica, ni con la comprobación matemática, ni con la compenetración entre las personas. Estos modos de experiencia también aportan cada uno sus cualidades al conocimiento de sí mismo, pero la modalidad experiencial de la conformación tiene algunas características que la hacen irreductible a las anteriores.

Para san Agustín, el mundo griego ignora de alguna manera el conocimiento de sí misma que una persona puede alcanzar. El hombre griego se ignora a sí mismo en lo que es más propio de sí mismo y "mira" hacia fuera, para verse en el reflejo de los demás. Pero conocerse desde las cosas y desde las personas, sólo

${ }^{13}$ Zubiri, X. (1986). Sobre el hombre (SH), ed. de I. Ellacuría. Madrid: Alianza Editorial.

${ }_{14}$ Zubiri X. (1992). Sobre el sentimiento y la voluntad (SSV), ed. de D. Gracia. Madrid: Alianza Editorial: 321-391. Stein, E. (2004). Sobre el problema de la empatía. Madrid: Trotta. Scheler, M. (1977). Esencia y formas de la simpatía. Buenos Aires: Losada.

${ }^{15}$ Zubiri, SSV, 1992: 21-193. 
desde fuera de sí mismo, es en última instancia un recurso incompleto y un fracaso (Conill, 2008: 51).

Porque "no es el hombre (solamente) un trozo de la naturaleza, sino algo consistente por sí mismo" (Zubiri, SPFOE, 2002: 52). Como dice Zubiri: "El hombre tiene dos modos de existir entre las cosas: Cuando vive en "olvido" (de sí mismo, sin mirarse hacia dentro de sí), vive en las cosas al modo griego (siendo así una cosa más entre otras, con sus particularidades), y cuando vive en "recuerdo" (pendiente de sí interiormente), vive en el espíritu y es extraño al universo" (Zubiri, SPFOE, 2002: 67). Claro que aquí no se trata solamente de un saber de sí, sino de un modo de existencia para uno mismo, o de un saber como forma de vida personal de cada cual.

Probablemente el concepto de "persona" sea decisivo a partir del cristianismo, como una manera de recoger la perspectiva que se abre en la interioridad de los hombres vueltos hacia sí mismos. "Naturaleza y esencia (physis y ousía) no se identifican con persona (hypóstasis). No basta decir "lo que" una cosa es; hay que decir también en qué consiste el "quién", de quién es aquello que la cosa es" (Conill, 2008: 52-53).

Frente a los griegos, la entrada de la persona en su intimidad personal es una situación metafísica novedosa. "Nociones como las de "persona" y "espíritu" que rebasan los conceptos de la metafísica griega desarrollada hasta entonces en versión física y ontológica" (Conill, 2008: 53).

A partir de Descartes, la modernidad y sobre todo su culminación en el racionalismo y después idealismo alemán, es una entrada del Espíritu en sí mismo, el yo, el sujeto, radica de alguna manera en el saber sobre sí mismo.

Repara en ti mismo; aparta tu mirada de todo lo que te rodea y dirígela hacia tu interior; esa es la primera exigencia que la filosofía hace al principiante. No se habla [aquí] de nada que esté fuera de ti, sino únicamente de ti mismo (Fichte, Primera Introducción a la Doctrina de la Ciencia, 1) (citado en Rivera de Rosales, 1994: 12).

Y esta persona en su interior, es proclive a la construcción de esbozos sobre su realidad profunda, y al intento de insertarlos probatoriamente en su realidad personal en su vida. Es la probación física de la conformación de sí mismo. 


\section{Conclusiones}

A lo largo de su evolución intelectual, hay que decir que Zubiri mantiene que la idea lógica y racional que nos hagamos finalmente de nosotros mismos es una idea en gran medida "construida". Pero construida a partir de una primaria aprehensión intelectiva de realidad de un "mî", "realidad mía" o "intimidad" (Zubiri, IRE, 1984: 101-109).

Esas ideas construidas que elaboramos de los contenidos de mí mismo se incluyen también en lo que es uno mismo, son parte de mí mismo en tanto que actividad intelectiva que uno mismo está realizando sobre sí mismo.

Para Zubiri hay una inmediatez del alma o psique para sí misma (como pretendía Descartes y una buena parte de la filosofía posterior a él), como la hay también para el organismo o cuerpo. Pero una inmediatez de su formalidad de realidad, sin una transparencia manifiesta a sus contenidos, solamente con un acceso limitado a los contenidos y un camino difícil hacia ellos.

Y es parte de mí mismo también la idea que me hago de otras personas. Los demás están en mí mismo, y yo estoy en los demás en la idea que los demás se hacen de mí. El "mí" adquiere por tanto unas dimensiones que sobrepasan ampliamente el solipsismo, ya en cuanto a su realidad primaria psico-orgánica, ya con las construcciones ideativas en las que se constituye secundariamente su contenido.

Estrictamente no habría una anterioridad de lo individual a lo interpersonal y a lo social, ni viceversa. Todas ellas son dimensiones que emergen de una primaria realidad que las incluye o desde la que emergen (Zubiri, Tres dimensiones del ser humano: individual, social, histórica (TDSH) 2006: 111).

Sobre una primera aprehensión de mí mismo como formalidad real, aprehensión primordial de realidad, y para solventar la incompletitud de su contenido, las personas se "figuran" cómo "sería" y cómo "podría ser" este sí mismo (o las cosas o las personas aprehendidas en su caso) en cuanto a sus contenidos. Figuraciones irreales que tendrá que poner cada uno a prueba en un segundo momento intelectivo en la experiencia de realidad (Zubiri, HRI, 2005: 158). 
El logos analiza lo que las cosas aprehendidas son "en" la aprehensión, entre otras cosas reales aprehendidas. La razón se ocupa de lo que esas cosas son allende la aprehensión, "en la realidad". "Pensar" es la actividad de la modalidad de intelección sentiente que lamamos razón (Zubiri, IRA, 1983: 25).

Es el paso de la realidad dada en impresión, en logos, a la realidad más allá de la aprehensión, en razón. Seguimos estando en la formalidad de realidad aprehendida en aprehensión primordial.

A diferencia del pensar sobre las cosas y otras personas, las figuraciones sobre sí mismo pueden optar a un modo de experiencia que es sólo propio de la vida interna de una persona, la conformación. Bien es cierto que el saber sobre mí mismo se obtiene en los experimentos científicos, en las experiencias de las ciencias del espíritu, en las comprobaciones matemáticas y estadísticas, en la compenetración con otras personas. Todas ellas son experiencias de un enorme valor y alcance. Pero el modo de experiencia exclusivo de la vida interna de una persona es la "conformación" de su propia realidad.

Sólo el esbozo de lo que yo "podría ser" insertado en mí como conformación es lo que constituye la forma de conocerse a sí mismo. Evidentemente, es una conformación en el orden de la actualización de mi propia realidad. Difícil operación este discernimiento de sí mismo. Es discernimiento en probación y en conformación (Zubiri, IRA, 1983: 257).

\section{Agradecimientos}

A los Directores de mi Tesis Doctoral, Prof. D. Jacinto Rivera de Rosales Chacón, y Prof. D. Antonio González Fernández, por la dirección de la misma ${ }^{16}$, en la que se apoya la investigación de este escrito.

\footnotetext{
${ }^{16}$ Alberdi Sudupe, Jesús. Del saber sobre sí mismo en Xavier Zubiri. En: http://e-spacio. uned.es/fez/view/tesisuned:ED-Pg-Filosofia-Jalberdi. Consultado el 26-04-2021.
} 


\section{Bibliografía}

Carruthers, P. (2011). The Opacity of Mind: An Integrative Theory of Self-Knowledge, Oxford: Oxford University Press.

Coliva, A. (2012). The Self and Self-Knowledge, Oxford: Oxford University Press.

Conill, J. (1991). El enigma del animal fantástico, Madrid: Tecnos.

- (1998). "Concepciones de la experiencia”, en Diálogo filosófico 41, 148-170.

- (2008). "Experiencia hermenéutica de la alteridad", en En-Claves del pensamiento II, 4, 47-66.

Descartes, R. (1977). Meditaciones metafísicas con objeciones y respuestas, Madrid: Alfaguara.

Fernández, J. (2013). Transparent Minds: A Sudy of Self-Knowledge, Oxford: Oxford University Press.

Ferraz Fayos, A. (1988). Zubiri: el realismo radical, Madrid: Cincel.

GonzÁlez, A. (1999). “La memoria: aproximación filosófica”, en Voces del tiempo 32, 13-18.

- (2013). Surgimiento. Hacia una ontología de la praxis, Santafé de Bogotá: Ediciones USTA.

— (2015). "Mismidad de acto: Aristóteles, Heidegger y Zubiri”, Pensamiento 71, 353367.

Gracia, D. (2007). "La realidad (El momento noemático de la aprehensión humana)". En: Gracia D. (2007). Voluntad de verdad (Para leer a Zubiri), Madrid: Triacastela, 169-211.

Laplanche, J., Pontalis, J.-B. (1983). Diccionario de psicoanálisis, Barcelona: Labor.

Marquínez Argote, G. (2006). "Realidad, historia de una palabra desde sus orígenes latinos hasta Zubiri”, en Cuadernos salmantinos de filosofía 33, 145-180.

Pintor-Ramos, A. (21983). Génesis y formación de la filosofía de Zubiri, Salamanca: Publicaciones Universidad Pontificia de Salamanca. 
- (1994). Ámbito de la realidad en Zubiri, en: Pintor-Ramos, A. (1994). Realidady verdad. (Las bases de la filosofia de Zubiri), Salamanca: Publicaciones Universidad Pontificia de Salamanca, 56-71.

Ricoeur, P. (2003). La Memoria, la Historia, el Olvido, Madrid: Trotta.

Rivera de Rosales, J. (1994). "Sujeto y realidad. Del Yo analítico substante al Yo sintético transcendental”, en Daimon. Revista de Filosofía 9, 9-38.

SCHeLer, M. (1977). Esencia y formas de la simpatía, Buenos Aires: Losada.

Stein, E. (2004). Sobre el problema de la empatía, Madrid: Trotta.

Zubiri, X. (1984). Inteligencia sentiente. Inteligencia y realidad (IRE), Madrid: Alianza Editorial.

— (1982). Inteligencia y logos (IL), Madrid: Alianza Editorial.

- (1983). Inteligencia y razón (IRA), Madrid: Alianza Editorial.

- (1984). El hombre y Dios (HD), ed. de I. Ellacuría, Madrid: Alianza Editorial.

- (1986). Sobre el hombre (SH), ed. de I. Ellacuría, Madrid: Alianza Editorial.

- (1987), Naturaleza. Historia. Dios (NHD), Madrid: Alianza Editorial.

- (1992). Sobre el sentimiento y la volición (SSV), ed. de D. Gracia, Madrid: Alianza Editorial.

- (2002). Sobre el problema de la filosofía y otros escritos (1932-1944) (SPFOE), ed. de G. Marquínez Argote, Madrid: Alianza Editorial.

- (2005). El hombre: Lo real y lo irreal (HRI), ed. de J. Conill, Madrid: Alianza Editorial.

- (2006). Tres dimensiones del ser humano: individual, social, histórica (TDSH), ed. de J. Corominas, Madrid: Alianza Editorial.

Este trabajo se encuentra bajo una licencia de Creative Commons ReconocimientoNoComercial-SinObraDerivada 4.0 